\title{
Bridging social capital as a resource for rural revitalisation in China? A survey of community connection of university students with home villages
}

\author{
Bin $\mathrm{Wu}^{1 *}$, Linghui Liu ${ }^{2}$ and Chris James Carter ${ }^{1}$
}

1. Nottingham University Business School, Nottingham, UK

2. University of Electronic S\&T of China, Chengdu, China

\section{Abstract}

Rural China faces many challenges, including outmigration, brain drains, and the hollowing out and decline of villages. This paper offers a response by drawing attention to the phenomenon of "community connection" among migrants in urban areas who try to keep their identity and attachment to home communities in the countryside. From the perspective of bridging social capital, we argue that community connection is a potential resource for rural revitalisation. The value and conditions of using community connection are revealed through a survey conducted with over 1200 university students in China, coming from a rural family background. This paper contributes to the literature in the following aspects: First, community connection provides a foundation upon which bridging social capital can be linked with and used for the development of home community, an important condition for successful rural revitalisation. Second, the potential of community connection requests in recognising a sense of community among migrants who are attaching to, and willing to bring external resources into, home communities. Third, a sense of community varies greatly with geographic location and the social group with which migrants belong to. A greater sense of community and place attachment is more likely found amongst those coming from remote villages and rural poor, whose livelihoods are heavily dependent upon traditional agriculture. Furthermore, differences in a sense of community may lead to different approaches or attitudes to ongoing land transfer in the countryside. Policy implications, research limitations and directions of further research are discussed.

Key words: bridging social capital, sense of community, place attachment, community connection, rural revitalisation, China

\footnotetext{
${ }^{*}$ Corresponding author: Dr. Bin Wu, Haydn Green Institute for Innovation and Entrepreneurship (HGI), Business South Building, Jubilee Campus, Nottingham, NG8 1BB, U.K. Email: bin.wu@nottingham.ac.uk. This paper has been accepted by Journal of Rural Studies.
} 


\section{Introduction}

Due to urbanisation, industrialisation and globalisation over the preceding decades, rural China faces many challenges, of which outmigration and brain drains are amongst the most significant. To cope with these challenges, there has been a call for rural revitalisation in order to attract and increase essential resources to its countryside, including human capital (Long and Liu, 2016; Long, et al., 2016; Li, et al., 2017).

Given the multiple dimensions of rural revitalisation in China, this paper draws attention to the phenomenon of "community connection" among migrants in urban areas who seek to maintain their identity and attachment with home communities in the countryside. Evidence from numerous surveys conducted in urban areas confirm the existence of community connections among rural migrants, as the majority of respondents often do not want to give up their rural hukou (Wang and Li, 2012; Hao and Tang, 2015) and some migrants who have already gained an urban hukou have even expressed a wish to return their status as rural residents (Li, 2011). Furthermore, many university students with a rural family background share similar attitudes in terms of maintaining their rural hukou rather than changing it to urban status, even though they are free to do so (Bao and Wang, 2017). Whilst many scholars attribute such phenomena to the soaring market value of rural land, this view may underestimate the complexity and diversity among rural migrants (both migrant workers and university students) of their links with home communities on the one hand, but also the value or potential for rural development and revitalisation on the other.

The phenomenon of community connection to rural community offers an opportunity to rethink the interconnections between rural and urban development, and the implications for sustainable rural development in the context of China; an excellent case that represents rapid urbanisation at the expense of its countryside's decline (Li, et. al.,2018). From the perspective 
of social capital (Bourdieu, 1986), we argue that community connection can be viewed as a potential resource for rural development and revitalisation besides conventional resources (e.g. physical, financial, and human capital), whilst the release of the potential is dependent upon many conditions on both sides of individuals and home communities. Whilst overwhelming attention has been paid to building social capital in facilitating mutual trust and collective actions within communities, less effort has been made to external social connection or bridging social capital, its existence, distribution, and potential contribution to rural development and revitalisation (Li at al., 2018; Prayitno et al., 2014). This paper attempts to fill the gap by aiming to address the following questions: What is the relationship between community connection and bridging social capital in the discourse of rural revitalisation? How can bridging social capital be recognised and identified for home development?

These research questions are examined through a combination of a literature review and a survey of university students in China with rural family backgrounds. The core arguments of this paper are organised as follows: the next section provides a critical review of the literature relating to bridging social capital, sense of community, and place attachment. Section 3 then provides information on the research design and survey methodology. The survey findings are presented in Section 4 and their implications for rural revitalisation are subsequently discussed in Section 5. The paper concludes with a summary of the research findings, key limitations and directions for future research.

\section{Literature review}

In the context of urbanisation, migration, and rural decline, rural revitalisation in China may be best described as a process of "rural restructuring", referring to "the reshaping of social and economic structures in rural areas during the late twentieth century and early twenty-first century produced by various, interconnected processes of change including the declining 
economic significance of agriculture, the rise of the service sector, urban to rural migration, and so on" (Woods, 2009). Rural restructuring, furthermore, contains many dimensions, of which social restructuring is key to coping with various challenges, from the dissemblance of traditional village communities to reconstructing new social structures and organisational systems for more optimal use of resources and opportunities, both internally and externally. From the perspective of social restructuring, the relevant literature is divided into three strands: bridging social capital, sense of community, and place attachments.

\subsection{Bridging social capital for rural restructuring}

Social capital is important for rural restructuring because the former is related to, and can be converted into, other forms of capital. Social capital, however, is a complex and multilayered concept, to which many different definitions and understandings have been assigned. For instance, Bourdieu (1986: 248) defines the concept as "the aggregate of the actual or potential resources which are linked to possession of a durable network of more or less institutionalised relationships of mutual acquaintance or recognition." Conversely, Putnam (1995: 67) defines social capital as "features of social organisation such as trust, norms and networks that facilitate coordination and cooperation for mutual benefit".

Social capital can be further distinguished into two types: bonding social capital, which creates the possibility for effective collective action within a community, and bridging social capital, which can be used to draw upon outside resources of expertise and financial capital. Regarding the latter, Onyx (2005:5) suggests "we need to reconcile and reconnect small and urban communities in new, dynamic ways, in order to avoid large islands of have and have-nots" in rural communities. 
The location of social capital is an important dimension to understand, especially as to the nature and function of social connections within or outside of a person's community. In this regard, internal social capital refers to social connections to organisations and/or influential individuals within one's community with access to social support or available resources. In contrast, external social capital denotes social connections to organisations and/or influential individuals outside of one' community with access to more diverse resources (Story and Carpiano, 2017: 114). Compared with the strengths of the former intracommunity form of connections, the latter external connections are also important because they provide a channel through which to gain new information, resources, and opportunities that are beyond the expectation of rural communities.

From Bourdieu's perspective, it is noted that social networks are not a natural given, and as such they must be constructed through investment strategies oriented to the institutionalisation of group relations. This differs markedly from Putnam's perspective, which focuses on social capital within social structures. However, according to Levien (2015: 77), Putnam's theory of collective social capital is unable to “explain how networks, norms, and trust interact in a process of social-economic change", to which Bourdieu's theory of individual social capital could provide "an alternative model".

For the purpose of rural revitalisation, we focus on bridging social capital with an emphasis on the actual or potential functions of individual social connections outside of the home communities. A research question arises here with regards to the role of individual social capital in the discourse of rural revitalisation. Specifically, what is the relationship between community connection and bridging social capital?

\subsection{Sense of community}


The concept of bridging social capital cannot be fully understood unless the term community itself can be clearly defined and explained. Community psychologists, such as Perks and Long (2002), offer a framework for social capital analysis which contains four dimensions: sense of community, collective efficacy/empowerment, citizen participation, and neighbouring (cited from Prayitno et al., 2014: 545). With our focus on the relationship between migrants and their home community, we view this theoretical dimension relating to sense of community as being especially relevant to this paper.

As defined by McMillan and Chavis (1986: 9), sense of community is "a feeling that members have of belonging, a feeling that members matter to one another and to their group, and a shared faith that members' needs will be met through their commitment to be together". A core element of this concept is membership, referring to "one's sense of belonging and to a sense of confidence that one has as member as well as the aspects of acceptance from the group that facilitates belonging." (McMillan, 1996, 315). Lately, McMillan uses the term spirit to replace membership, emphasising emotional safety ("the community provides the acceptance, empathy, and support for members to speak their truth and be themselves"); boundaries (or membership that delimit "us" from "them"), sense of belonging, and cognitive dissonance (ibid: 315-318). In particular, McMillan proposes that cognitive dissonance facilitates a sense of community in three ways: it enhances a member's confidence; creates a sense of entitlement; and builds loyalty to the group.

Sense of community can help us to better understand the relationship between external and internal social connections in two key ways: First, it is unlikely that all social connections outside of the community can be viewed as bridging social capital. Rather, only those individuals who have a "sense of community" in mind, or shared values, interests, and responsibilities within the community, may be trusted and accepted by the community 
as its members. Second, the boundaries of community are relative and dynamic, dependent upon the establishment and development of mutual trust between individuals and community.

According to McMillan (1996: 318), the spirit of a sense of community can be viewed as a spark, which cannot become a flame or fire unless the potential members and community are able to influence one another. Accounting for the large scale levels of outmigration and rural-urban inequality in China, it raises the following question: How can sense of community among individuals outside of the community be recognised and measured?

\subsection{Place attachment}

In order to address the preceding research question, we can look to the concept of place attachment; defined as the "positive bonds developed from behavioural, affective, and cognitive ties between individuals or groups and multiple levels of their socio-physical environment" (Brown et al., 2012). These bonds are held to be "integral to individual and community aspects of self-identity and provide a source of stability and change for individuals and communities alike" (Prayitno, et al., 2014:545). Therefore, we may anticipate that the greater the feeling of place attachment within the sense of community, the more individuals may want to interact with the community.

The concept of place attachment also sheds new light on the relationship between individuals outside the community and at its margins, as "[people] and their relationships are embedded within physical contexts so that the very meaning of social process cannot be abstracted from place, but be informed, constrained, and nourished by places" (Brown et al., 2012 184). Place attachment as "positive bonds to place" may be more important for 
those in poor areas where "individuals can become attached to their homes regardless of social class and housing dilapidation". It is noteworthy that despite "a sense of positive identity, security, and continuity in place attachments, the very foundation of those bonds is constantly changing, so place attachments also undergo change and transformation" (ibid).

Brown et al. (2012: 188) identify a knowledge gap in "understand[ing] how to engage place attachments to protect places...against distant threats such as the destruction of rainforests across the globe, or mobilising against hidden threats...[and] given increasing population mobility [how to] bring diverse peoples together". Along this line, we pose the following question in relation to rural restructuring: How are place attachments distributed among individuals in terms of geographic location of their community and the social grouping of the families to which they belong?

\section{Research background, framework and survey methodology}

\subsection{Outmigration, brain drains and rural revitalisation in China}

China has experienced rapid urbanisation, as indicated by the share of urban residents in the total population rising considerably from $36.2 \%$ in 2000 to $56.1 \%$ in 2016 . However, in contrast to this urban residential population, the growth of the urban hukou registered population in the same period accounted for only $24.7 \%$ and $39.9 \%$ in the respective years. This resulted in an increasing gap of $11.5 \%$ to $16.2 \%$ over the same period between the residential and registered populations in urban China. These gaps reflect a serious issue facing Chinese society: that there is a large number of so-called rural migrant workers who do not settle down and integrate into urban societies. According to official statistics, the number of rural migrant workers who left their home villages for more than six months increased nationwide from 140.41 million in 2008 
to 169.34 million in 2016 (NBS, 2009; 2017). Given that the typical profile of these rural migrant workers are young and well-educated individuals, the large scale of rural-urban migration has inevitably contributed not only to the rapid advancement of urbanisation, but also to 'hollowed villages' and a 'brain drain', leaving village communities predominantly consisting of women, children, and the aged.

Student migration, referring to those who are born in the countryside and have access to higher education or vocational education in urban areas, is another major channel of outmigration from rural China. Compared to rural migrant workers, student migrants are more likely to become urban citizens after they graduate. The number of rural students in tertiary education increased markedly from just over 1 million in 1999 to 3.85 million in 2014, with an accumulative total of 49.33 million during the period. It is estimated that student migration simultaneously contributed to $15 \%$ of urban population growth and $23 \%$ of rural population decline in the same period (Liu, 2016a).

In contrast to rural migrant workers, rural students are entitled to change their status from rural to urban hukou automatically once they have gained access to tertiary education, according to the Chinese hukou regulation that has been in effect since the late 1950s. From 2003, however, this regulation has been amended to give the choice to rural students in deciding whether to change their hukou status from rural to urban. In response to this policy adjustment and other factors, a large number of rural students have retained their rural hukou and there is an increase in the return migration of students in recent years (Liu, 2016b).

New momentum in return migration, albeit relatively small in quantity, cannot be separated from policies enacted by the Chinese government. In 2008, the central government issued a policy to encourage university graduates to serve grassroots organisations in the countryside (so-called cunguan or 村官 in Chinese). By 2013, a total of 410,000 university 
graduates, funded by the government, returned to the countryside, accounting for about onethird of administrative villages across China. In 2015, the State Council introduced a further series of favourable policies, such as financial and social security subsidies, employment support policies, financial services, venture capital funds. These aimed to encourage migrant workers, university students, retired soldiers and other young people to return home to set up their own businesses, or engage in agricultural modernisation, rural industrialisation or village reconstruction projects. In 2016, the National Development and Reform Commission, together with ten other Ministries, went even further in supporting return migration by encouraging rural migrant workers and university students to participate in 'rural urbanisation' demonstration projects in 116 selected counties across the country. At the same time, the Ministry of Agriculture offered a series of training programmes for the development of a "new generation of farmers", targeting trainees who were returnee migrant workers and university graduates (Hua, 2016). This initiative aims to increase specialisation, standardisation, and the scaling up and intensification of agricultural production (Ye, 2015: 329).

\section{2 "Community connection”: a working definition}

Aligned with the concept of bridging social capital, the term community connection can be viewed as external social connections, referring to any links, interactions, or shared interests between migrants and members of home communities in a variety of aspects: economic (e.g. land, property, production and business); social (kindship, friendship, neighbourhood); psychological (perception, attitude, feeling, and affiliation); and cultural (history, value, and

identity). The concept of community connection provides a foundation upon which sense of community and place attachment can be developed and used for meaningful communication, interaction, and even collaboration between individuals and the community. 
In the context of migration and rural transformation in China, community connection can be recognised by one or many of the following characters, detailed below:

1) share of access or entitlement to share the benefits from collective land;

2) shared identity with members of home communities (e.g. rural hukou);

3) sharing of responsibilities (moral, economic, social) at various levels, individual, family, group, and village collective;

4) shared values with home communities, such as village history, tradition, and culture.

The concept of community connection is not uniquely novel but rather rooted in Chinese society for thousands of years. For instance, in Chinese history, there are many phrases (e.g. 光宗耀祖 guangzong yaozhu, bringing glory to the family and ancestors; 衣锦还乡 yijin huanxiang, returning home after having won high honours and social recognition) and numerous stories about how successful outmigration, and student migration in particular, bring glory (honour) to one's ancestors with a wide range of benefits; and not only to family members but home communities as a whole. With a focus on the challenges and dilemmas facing rural China today, bridging social capital provides a useful lens to understand the links, interactions, and potential of university students for their home development.

\subsection{Analysis framework, indicators and hypotheses}

In connection with the research questions presented throughout the previous sections, we pose a framework which contains three dimensions, associated with a few key indicators (or key variables) and hypotheses to measure the existence, distribution, and potential function of bridging social capital among community connection.

Sense of rural community. This refers to emotional, psychological or cognitive belonging, dependence or resonance of migrants with their home community regardless of the 
status of hukou, employment, and hierarchy in urban society. Compared with the choice of hukou status which may be influenced by institutional (e.g. hukou reform) or economic (e.g. market value of rural land) factors, the sense of community is more related to the subjectivity of migrants in terms of respecting and appreciating the history, culture, and social norms of home community. In relation to the maintenance of rural identity, in particular, we use an indicator of personal preference between rural and urban lifestyle as the dependent variable, which reflects their attitude and value orientation. The higher the percentage of preference for rural lifestyle means the higher of bridging social capital existing among those with community connection.

Place attachment to home community. Sense of rural community varies greatly among rural migrants, which can be measured from place attachment. Taking into account heavy pressures from competition, individualism, and commercialisation in urban China, place attachment emphasises traditional culture, village collaboration, and common prosperity. It is reasonable to assume that such a traditional perspective could be more popular in remote villages, where traditional farming and low incomes are dominant. Thus, we take two indicators as independent variables to measure place attachment: remoteness of home village to county town, and traditional farming. Accordingly, we draw two hypotheses for statistical test:

Hypothesis 1: Preference for rural lifestyle is more likely found among those from families in remote villages than among those from villages near urban centres.

Hypothesis 2: Preference for rural lifestyle is more likely found among those from traditional farming households than among those from non-farming households.

Difference in viewing land transfer. The interconnection of bridging social capital with home communication development can be illustrated from different opinions or attitudes to land transfer in home villages. Given that the process of land transfer is closely related to bonding social capital, different attitudes to farmland transfer can be distinguished through two 
choices: land transfer within villages to enhance community cohesion, or land transfer to external investors to gain higher renting fees. Therefore, we propose:

Hypothesis 3: Preference for rural lifestyle is more likely found among those holding access to collective land who give their choice of land transfer to internal transfer compared with counterparts who choose external transfer, who will in turn be more likely to prefer urban lifestyle.

\subsection{Survey design and data analysis}

The existence, distribution, and function of bridging social capital is revealed through a survey distributed to over 100 Higher Education Institutions (HEIs) across China in the period of 20122013. Adopting a standard procedure, local contacts in different HEIs were responsible for mobilising, pursuing, and disseminating the surveys to targeted students with rural family backgrounds, including those who had recently started working in an urban area but kept in touch with student groups on the campuses, or those who had completed their courses and were searching for work in an urban labour market. In practice, the questionnaires were widely disseminated through two channels: before or after teaching in classrooms. This allowed all students with rural backgrounds to participate voluntarily in the survey and for student networks to be drawn upon, with participants able to contact their friends and classmates in other universities or cities, even if they had graduated, to participate in the survey. A total of 1421 surveys were disseminated to the targeted population, with a return of 1219 valid surveys representing an $85.78 \%$ respondent rate.

SPSS software was used to first analyse the relationship between a number of variables, including: lifestyle preference, the change of rural to urban houkou, status of respondents in studying or labour market, access to farmland, location of home village, family production structure and income level, location and hierarchy of HEIs, degree of HE courses, and 
psychological pressure of respondents in urban areas. As there was no statistically significant relationship found between the variables of changing (or keeping) rural hukou, lifestyle preference, and the access to farmland, we used a logistic regression model to test Hypotheses 1 (that preference for rural lifestyle is more likely to be found among those from families in remote villages compared to those near urban centres) and 2 (that preference for rural lifestyle is more likely found among those from traditional farming households than those from nonfarming households). In both cases, lifestyle preference was taken as the dependent variable.

The main independent variables used in our analysis included: location of village to county town $(<10 \mathrm{~km}, 10-20 \mathrm{~km}, 20-30 \mathrm{~km}$, and $>30 \mathrm{~km}$, with $<10 \mathrm{~km}$ as the baseline group) and family livelihood system (farming only, farming and non-farm, farming < non-farm, and nonfarm only, with farming only as the baseline group). Other independent variables included: age, gender, current status (student or graduated), change of hukou, location of HE institute (within or outside of home providence), type of HE courses (vocational, undergraduate, and postgraduate degree, of which vocational education was taken as the baseline group), rank of HEI (vocational, regular, and national key, with vocational taken as the baseline group), and pressure of respondent to urban life (not at all, ok, big, and heavy, with heavy as the baseline group).

For Hypothesis 3, we selected participants who had access to collective farmland to examine the relationship between their attitudes to land transfer and lifestyle preference. Specifically, we predict that preference for rural lifestyle is more likely found among those who give their choice of land transfer to internal transfer compared with counterparts who choose external transfer.

\section{Research findings from data analysis}

\subsection{Baseline and background information}


Table 1 provides baseline information on the survey samples. Of the total 1219 valid respondents, we included those graduates who were either successfully employed or were searching for employment in an urban area, in order to contrast the differenced with current students in terms of attitudes and perceptions to home communities. We included a gender dimension to test differences in terms of their lifestyles and social ties with home communities. From the perspective of employment opportunities in urban areas, we considered differences in the students' attitudes and perceptions to rural communities in relation to different types of education, including postgraduate (both Master and $\mathrm{PhD}$-level degrees), undergraduate (leading to Bachelor's degree), and vocational (2-3 year Higher Education certificate) degrees. The results indicate that around three-quarters of the respondents were pursuing undergraduate courses, one-fifth within vocational education, and the remainder $(6.5 \%)$ studying postgraduate courses.

Table 1 Baseline information of samples

\begin{tabular}{llcc}
\hline Category & Item & $\mathrm{N}$ & $\%$ \\
\hline \multirow{2}{*}{ Status } & Studying & 1050 & 86.1 \\
& Graduated & 169 & 13.9 \\
\hline \multirow{2}{*}{ Sex } & Male & 656 & 53.8 \\
& Female & 563 & 46.2 \\
\hline \multirow{2}{*}{ HEI course type } & Postgraduate & 79 & 6.5 \\
& Undergraduate & 901 & 73.9 \\
& Vocational & 239 & 19.6 \\
\hline \multirow{2}{*}{ Location } & Within province & 733 & 60.6 \\
& Across province & 477 & 39.4 \\
\hline Total & & 1219 & 100 \\
\hline
\end{tabular}

Geographic distribution of samples was widespread with 27 out of 31 provinces, municipalities, or autonomic regions in terms of their home location. Together, Henan, Sichuan, and Hubei accounted for just over half of the sample. Furthermore, Table 1 shows that three-fifths of the respondents studied within the same province as their home, whilst the remaining two-fifths 
were living in different provinces, offering an opportunity to examine any differences related to education mobility across regional (provincial) boundaries.

Table 2 Characteristics of villages and households (\%)

\begin{tabular}{|c|c|c|c|c|c|}
\hline \multicolumn{2}{|c|}{ Village to county town } & \multicolumn{2}{|c|}{ HD economic structure } & \multicolumn{2}{|c|}{ HD income (yuan/year) } \\
\hline$<10 \mathrm{~km}$ & 27.0 & Farming only & 32.2 & $<20,000$ & 39.0 \\
\hline $10-20 \mathrm{~km}$ & 26.3 & Farm \& non-farm & 20.2 & $20-40,000$ & 29.1 \\
\hline $20-30 \mathrm{~km}$ & 19.2 & Non-farm > farm & 23.5 & $40-60,000$ & 15.8 \\
\hline$>30 \mathrm{~km}$ & 27.5 & Non-farm only & 24.2 & $>60,000$ & 16.2 \\
\hline Total & 100 & Total & 100 & Total & 100 \\
\hline
\end{tabular}

With regards to the heterogeneousness of the countryside and impact on community connection, Table 2 distinguishes different groups according to the remoteness of home villages (distance to county towns), the economic structure of household (HD), and annual income level.

Table 3 Zero-order correlations between main study variables

\begin{tabular}{lllllllllllll}
\hline Variable & 1 & 2 & 3 & 4 & 5 & 6 & 7 & 8 & 9 & 10 & 11 & 12
\end{tabular}

1. Pref. for urban 1

2. Age $\quad .04 \quad 1$

3. Gender $\quad .05^{*}-.08^{* * *} 1$

4. Income structure $.13^{* * *} \quad .01 \quad-.03 \quad 1$

5. Income level $\quad .13^{* * *} \quad .09^{* * *}-.08^{* * *} \quad .50^{* * *} \quad 1$

6. Distance to town $-.10^{* * *} \quad .01 \quad-.03 \quad-.20^{* * *}-.21^{* * *} \quad 1$

7. Pressure level $\quad .11^{* * *}-.15^{* * *} \quad-.01 \quad .12^{* * *} \quad .18^{* * *} \quad-.08^{* * *} \quad 1$

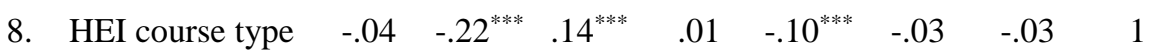

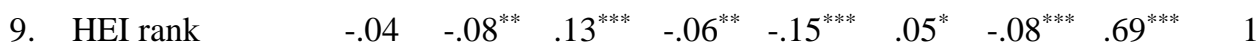

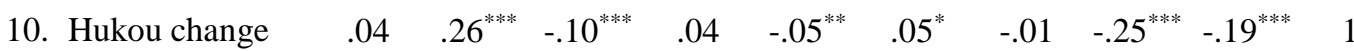

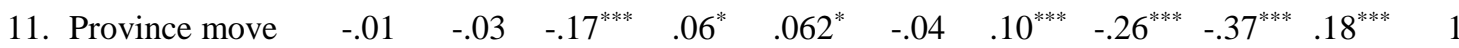




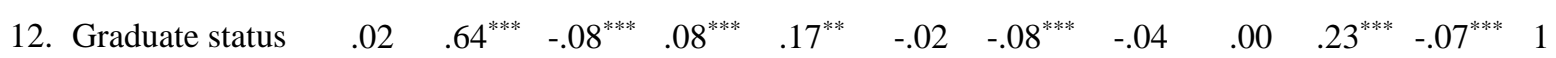

$* p<.05$ level, $* * p<.01$ level, $* * * p<.001$ level $; N=1219$

The correlation analysis presented in Table 3 confirms that HD economic structure and income level are significantly related $(r=.497, \mathrm{p}<.001)$, whilst both are correlated with village location $(\mathrm{r}=-.203, \mathrm{p}<.001$ and $\mathrm{r}=-.207, \mathrm{p}<.001$, respectively). Specifically, students from more remote villages appeared more likely to come from households with farming-centric economic structures and lower annual income. Preference for urbanised lifestyle was significantly related to gender $(\mathrm{r}=.05, \mathrm{p}<.05)$, HD economic structure and income level (both $\mathrm{r}=.13, \mathrm{p}<.001$, respectively), distance to town $(\mathrm{r}=-.10, \mathrm{p}<.001)$ and pressure level $(\mathrm{r}=.11, \mathrm{p}<.001)$, though not age, HEI course type, HEI rank, change in hukou, move of province or graduate status. Nevertheless, the relationship between preference for urbanised lifestyle and both rank of university and type of course did meet statistical significance at the less conservative $p<.10$ level $(\mathrm{r}=-.04, \mathrm{p}=.09$ and $\mathrm{r}=-.04, \mathrm{p}=.07$, respectively).

These findings tentatively indicate that in comparison with students in vocational education, those in regular and national key universities indicate greater preference for rural lifestyle. Such a phenomenon may be interpreted as the variation amongst students in terms of their understanding, perceptions, and confidence regarding the opportunity and future of their career development in urban areas. For those in vocational education, the aim of their career development is successful job hunting and settling down in urban areas. By contrast, students in regular and national key universities may pay more attention to resources, opportunities, and constraints of their career development in urban areas, and comparative advantages compared with their counterparts from an urban family background. Such a result seems to suggest that compared with those in vocational education institutes, students from ordinary and national key 
universities might be more interested in, or sensitive to, opportunities emerging in their home areas.

Furthermore, in relation to degree courses, these findings also tentatively indicate that the higher the degree participants studied, the greater their preference for urban lifestyle. This is matched with social norms or expectations: the higher the investment in human capital, the higher the expectation for the return either in higher salary or decent work in urban areas. Compared with the influence from the type and rank of HEIs described in the previous paragraph, this result emphasises the correlation between the investment in education and expected return from the urban labour market.

Table 4 highlights responses to three questions in the survey that relate to access to farmland and attitudes to land transfer in their home villages. It shows that nearly half of respondents had no access to farmland and for those who were entitled to have a responsible farmland, almost three-quarters supported the possibility of land transfer. For those in favour of this, around onethird identified relatives as the likely recipient, while almost two-fifths indicated selling for a high price. In terms of internal and external community boundaries, the preference given to land transfer within the community - represented by the 'Relatives' and 'Within group' options - appeared less preferable to beyond community boundaries, represented by 'High price' and 'Formal Sector' (45.8\% and 54.2\%, respectively).

Table 4 Relation between students and rural land

\begin{tabular}{l|c|rr}
\hline \multicolumn{1}{c|}{ Question } & Answer & \multicolumn{1}{|c}{} & $\%$ \\
\hline 1. Access to farmland? & Yes & 622 & 51.1 \\
& No & 596 & 48.9 \\
\hline 2. Willing for land transfer? & Yes & 436 & 72.7 \\
& No & 164 & 27.3 \\
\hline 3. Land transfer to whom? & Relatives & 152 & 34.6 \\
& Within group & 49 & 11.2 \\
& High price & 169 & 38.5 \\
& Formal sector & 69 & 15.7 \\
\hline
\end{tabular}


The survey suggests that just over three-fifths (61.5\%) of respondents indicated a preference for an urban lifestyle, compared to just under two-fifths (38.5\%) for rural lifestyle. Reflecting on Hypotheses 1 and 2, logistical regression was run to reveal the determinant factors behind the choice of lifestyle preference. The predictor variables included in the model were those found to be significantly associated with lifestyle preference at $p<.05$ level or greater in Table 3.

Table 5 Logistic regression of lifestyle preference (with rural preference as the baseline)

\begin{tabular}{|c|c|c|c|c|}
\hline & $\mathrm{B}$ & Odds Ratio & \multicolumn{2}{|c|}{$95 \% \mathrm{CI}$} \\
\hline $\begin{array}{l}\text { (ref.: male) } \\
\text { Female }\end{array}$ & $-.23 *$ & .80 & .63 & 1.01 \\
\hline \multicolumn{5}{|l|}{$\begin{array}{l}\text { Income structure } \\
\text { (ref.: Farm only) }\end{array}$} \\
\hline Farm \& non-farm & $-.35^{*}$ & .70 & .48 & 1.04 \\
\hline Non-farm > farm & -.27 & .77 & .52 & 1.13 \\
\hline Non-farm only & -.08 & .93 & .64 & 1.34 \\
\hline \multicolumn{5}{|l|}{$\begin{array}{l}\text { Income level } \\
\text { (ref.: < 20k) }\end{array}$} \\
\hline $20-40 \mathrm{k}$ & $-.43 * *$ & .65 & .43 & .98 \\
\hline $40-60 \mathrm{k}$ & -.27 & .77 & .51 & 1.16 \\
\hline$>60 \mathrm{k}$ & -.13 & .88 & .56 & 1.38 \\
\hline \multicolumn{5}{|l|}{$\begin{array}{l}\text { Distance to town } \\
\text { (ref.: }<10 \mathrm{~km})\end{array}$} \\
\hline $10-20 \mathrm{~km}$ & $.34 * *$ & 1.41 & 1.01 & 1.97 \\
\hline $20-30 \mathrm{~km}$ & .13 & 1.14 & .83 & 1.57 \\
\hline$>30 \mathrm{~km}$ & -.20 & .82 & .58 & 1.16 \\
\hline \multicolumn{5}{|l|}{$\begin{array}{l}\text { Pressure level } \\
\text { (ref.: Heavy) }\end{array}$} \\
\hline Big & -.56 & .57 & .28 & 1.17 \\
\hline Ok & -.04 & .96 & .48 & 1.94 \\
\hline None & -.01 & 1.00 & .48 & 2.04 \\
\hline Constant & 1.12 & & & \\
\hline Initial - 2 log likelihood & 1624.53 & & & \\
\hline Model - 2 log likelihood & 1570.65 & & & \\
\hline $\mathrm{Chi}^{2}$ & 53.88 & & & \\
\hline No. of degrees of freedom & 13 & & & \\
\hline Significance & .00 & & & \\
\hline
\end{tabular}




\begin{tabular}{lc} 
Nagelkerke $R^{2}$ & .06 \\
$\mathbf{N}$ & 1219 \\
\hline$p<.10$ level, $* * p<.05$ level, $* * * p<.01$ level.
\end{tabular}

Overall, the logistic regression model presented in Table 5 was statistically significant, $x^{2}(13)=53.88, p<.001$. The model explained $6 \%\left(\right.$ Nagerlkerke $\left.R^{2}\right)$ of the variance in lifestyle preference and correctly classified $63.3 \%$ of cases. A number of observations can be drawn from the findings for each of the predictor variables. First, compared with the male respondents, female counterparts were 0.8 times more likely to indicate a preference for urban lifestyle $\left(x^{2}(1\right.$, $\mathrm{N}=1219)=3.40, p=.065)$. This can be interpreted as the influence of traditional culture in rural China in which females will leave their home and resettle in the villages of their husbands once married. As a result, community connection among male students could be stronger than female due to the differences in various aspects from economic (e.g. access to farmland and accommodation land), social (e.g. family responsibility), and cultural (e.g. identity) terms.

Second, taking into account the variety of village environments and significant impact on the preference of their lifestyle $\left(x^{2}(3, \mathrm{~N}=1219)=16.35, p=.000\right)$, students from remote villages are more likely to prefer rural lifestyle. In particular, students located between 10 to $20 \mathrm{~km}$ from their county town were almost one-and-a-half times more likely to prefer a rural lifestyle compared to those based less than $10 \mathrm{~km}$ away. Such a result shows that the closer to county town, the stronger the preference for urban lifestyle, leading to higher chances for their choice of urban lifestyle. This result confirms Hypothesis 1, that preference for rural lifestyle is more likely to be found among those from families in remote villages than among those from villages near urban centres.

Third, from the perspective of the family economic structure, the correlation analysis in Table 3 indicated that students from non-farm households are more likely to give their preference for urban lifestyle than those whose family livelihoods that are heavily dependent 
on agricultural income. With a statistically significant effect of income structure found $\left(x^{2}(3, \mathrm{~N}\right.$ $=1219)=19.85, p=.000)$, Hypothesis 2 was, therefore, confirmed. Table 5 shows that in particular, students from mixed households of farm and non-farm income were 0.7 times more likely to prefer an urban lifestyle compared to their counterparts from farm-only households. Bearing in the mind the sizable correlation between household economic structure and income level $(\mathrm{r}=.50, p<.001)$, this seems to suggest: a) students from non-farmer households could gain more support from their families in terms of adaptation and integration into urban society; b) students from agricultural dominant families may be more familiar with and/or involved in agricultural production, thereby giving them greater appreciation for a rural lifestyle.

Finally, choice of lifestyle preference was found to be significantly related to respondents' reactions, or their perceptions of psychological pressures from living in urban areas $\left(x^{2}(3, \mathrm{~N}=1219)=19.05, p=.000\right)$. As indicated by the correlation analysis in Table 3 , the greater the pressures students reported feeling in urban areas, the more likely they are to prefer a rural lifestyle. This result seems to confirm the deterioration of urban environments facing graduates, including the intensified competition in the labour market and soaring of housing price in recent years, on the perceptions and preparation for their settlement and integration into urban society in the future. Nonetheless, it also sheds new light on the possibility of return migration among some of students who feel the pressures of living in urban areas cannot be withstood.

\subsection{Land transfer and preference of lifestyle}

In relation to Hypothesis 3, Table 6 shows the association between lifestyle preference and land transfer among those who had access to collective farmland. Generally, students preferring an urban lifestyle gave more favourable responses to land transfer than their counterparts preferring a rural lifestyle $(75.7 \%$ vs. $67.9 \%, r=-.09, p<.05)$. Among those who gave the 
consent to land transfer, students preferring an urban lifestyle were more likely targeted at external investors who can offer a higher price for renting their farmland rather than internal investment $(59 \%$ vs. $40.6 \%, r=.14, p<.01)$. This was in contrast to those preferring a rural lifestyle who paid more attention to the possibility of land transfer within the community $(54.7 \%$ vs. $45.3 \%$ ). This seems to suggest different approaches between two groups: the former (preferring urban lifestyle) treats rural land as "assets" and land transfer as an opportunity to maximize the economic benefits and use this part of the economic income to support their own lives in the city. By contrast, the latter (preference for a rural lifestyle) view rural land as "resources" of rural development and land transfer as an opportunity to interconnect and enhance links with their relatives, friends, or other members of home community for a common future.

Table 6 Attitude of farmland transfer by preference of lifestyle

\begin{tabular}{c|cc|cc}
\hline \multirow{2}{*}{ Preference } & \multicolumn{2}{|c|}{ Land transfer? $(\mathrm{N}=600)$} & \multicolumn{2}{c}{ Scope of land transfer $(\mathrm{N}=439)$} \\
\cline { 2 - 5 } & No & Yes & Internal & External \\
\hline Rural & $32.1 \%$ & $67.9 \%$ & $54.7 \%$ & $45.3 \%$ \\
Urban & $24.3 \%$ & $75.7 \%$ & $40.6 \%$ & $59.0 \%$ \\
\hline Total & $27.3 \%$ & $72.7 \%$ & $45.8 \%$ & $54.2 \%$ \\
\hline
\end{tabular}

Note: the definition of the scope of land transfer is based upon the information in the bottom of Table 4 in which "internal" refers to either relatives or other members within the group, whilst "external" to either the high price of renting or formal sector.

\section{Discussion}

Having presented the findings from the survey data analysis, this section aims to discuss the key implications of the concept of community connection, and contribution to the debates of rural revitalisation in China and beyond.

\subsection{Understanding on rurality and rural revitalisation in China}

The concept of community connection calls for broadening our understanding on rurality and rural revitalisation in China in the $21^{\text {st }}$ century. The concept is created to describe and analyse external social connections and implications for rural communities. With a focus on rural 
students in universities, our survey confirms the existence of the community connection and impact on the majority of rural university students, which can be verified from many indicators, including: keeping rural hukou unchanged (involving three-quarters of the sample), the access to collective farmland (nearly one-half) and preference for a rural lifestyle (nearly two-fifths).

The above evidence seems to depart from conventional understanding of rurality, including: classically rural territories from the perspective of population density and spatial distribution, or a social-cultural approach which distinguishes between "urban" and "rural" societies "on the basis of residents' values and behaviours and on the social and cultural characteristics of communities." (Woods, 2005: 9). Conversely, we would like to emphasise the nature of complexity, overlapping, and transformation between rural and urban societies in the period of China's urbanisation and social transition. In this regard, a social representation approach which views rurality as socially constructed (Woods, 2005: 11) is more fitted to the reality of rural restructuring in China because it involves two-way flows of people, information, and investment across rural-urban boundaries. Accordingly, this paper sheds new light on the concept of rurality, which should include all people in rural and urban areas; not only migrants (migrant workers, students and others from countryside) but also urban residents without rural community background who share values, respects, and interests with rural communities.

Our research is also aligned with research findings from other papers including the persistence of rurality in urban China (Hao, et al., 2012; Chung, 2014; Kan, 2016). Interconnecting with research findings in this paper, it seems to suggest: a) there is an overlap between the two societies, urban and rural; b) the concept of community connection provides a useful lens to observe and analyse how two-way communication, interaction and cooperation between new migrants and home communities. Above results also support de Haas' observation that the "[latest development of migration studies] tend to maintain close links with their 
communities of origin over much longer periods than has previously been assumed, [and also] the development contribution of migration is not necessarily linked to the return of migrants" (de Haas, 2010: 246, emphasis added).

In relation to the debate of rural restructuring, the concept of community connection sheds new light on the dynamics of rural revitalisation, which requires more attention to those in urban areas who have social ties with home villages or who share mutual trust and interests with rural communities. In this sense, we support the notion of "ruralisation alongside urbanisation in China" (Li, et al., 2018) but would like to add an emphasis on 'brain gain' from those in urban areas who share values and commitment with rural inhabitants. Furthermore, the concept of community connection is not necessarily limited to rural migrants but can be applied to those urban residents who come to share the same interests, values, and social responsibilities with rural community members for a long term and common future.

\subsection{Interconnection between bridging and bonding social capital}

It would be a mistake to simply assume that all external social connections are valuable for the discourse of rural restructuring. This raises a theoretical question about the nature and value of, and conditions to use, community connection. Accordingly, we have brought together theories of social capital, sense of community, and place attachment for empirical data analysis. In relation with relevant debates, a number of research findings can be drawn as follows.

First, community connection contains an element of "rural hukou", symbolic for university students to keep their identity as "memberships" of rural community unchanged, and to distinguish themselves from other groups in urban areas. The fact that the majority of respondents keep rural hukou unchanged reflects compliance with the perspective of Bourdieu (1986) that rural students as individual social capital can be viewed as potential resources on 
the one hand, and the actual value of such connection to the community of origin is dependent upon a number of conditions which are to be further studied.

Second, the conditions of community connection for rural development and revitalisation can be taken through the theory of sense of community to reveal the feeling, belonging, commitment, and loyalty of individuals to the community of origin (McMillan and Chavis, 1986, McMillan, 1996). The fact that almost $40 \%$ of respondents preferred a rural lifestyle confirms: a) not all but some of community connection can be viewed as useful resources for rural development; b) there are some conditions existing between actual and potential resources; c) sense of rural community can be used as a key indicator to identify those who take care and may have interests in contributing to home community. In general, sense of community can be viewed as a point of interconnection between bridging and bonding social capital, a key condition for recognising and using community connection for rural revitalisation. Such a conclusion complements research findings from rural India (Levien, 2015) and Indonesia (Prayingtno et al., 2014), both of which show the necessity of the interconnection between bridging and bonding social capital for rural development.

Thirdly, the empirical evidence confirms that based upon the theory of place attachment (Brown et al., 2012), the variation of sense of rural community is closely related to geographic location (Hypothesis 1) and social group of the community of origin (Hypothesis 2). Accounting for the ongoing rural transition and restructuring in China, a number of considerations can be drawn from this finding. First, it confirms the necessity of the interconnection of bridging and bonding social capital due to the nature of two ways of interaction between individuals and communities: some rural communities may inevitably be in a process of decline in terms of bonding social capital to which it may be difficult for individuals outside to maintain their loyalty and belonging to the community. Second, it 
suggests community connection or bridging social capital play different roles in different locations and for different social groups within rural communities. Place attachment is particularly important for marginal areas and the rural poor, who suffer from shortage or constraints of geographic (locations), ecological (agricultural and climate conditions), physical (infrastructure), financial, and human (labour and talent) capitals. Such a conclusion is not new but is consistent with the theory of sustainable livelihood security (Carney 1998) and empirical research in the Loess Plateau (Wu, 2003; Wu and Pretty, 2004), which show the positive influence of social capital in sustainable development and poverty alleviation.

Finally, the findings of the survey data analysis seem to support the hypothesis that sense of community influences attitudes to farmland transfer in general, and place attachment may have a positive impact on community cohesion by favouring to land transfer internally, in

particular (Hypothesis 3). A certain level of caution is necessary in relation to this finding, however, as we are unable to fully examine the complicated factors behind land transfer, such as: agricultural production conditions, labour migration, economic environment, community organisation, and so on.

\subsection{Rebalancing rural-urban relationship}

The significance of the research findings summarised in the previous sections is not limited to how to recognise and identify the value of community connection for rural revitalisation, but also sheds new light on rebalancing the rural-urban relationship: an important condition for successful rural restructuring in China. In this regard, this paper contributes to the debate of rural revitalisation in the following aspects.

First, with regard to the interconnection between bridging and bonding social capital, this paper emphasises the importance of respecting, learning from, and emphasising the voices, needs, potential, and resources both within and outside of rural communities. For the latter, 
their external social connections in urban areas play a key role towards sustainable, endogenous, and bottom-up development. Such a point is meaningful and important, accounting for the domination of the top-down approach in addition urban professionals' view on rural restructuring, such as "new-typed rural urbanisation" (Ahlers, 2015), which often ignores the voice and value of rural communities.

Second, it also shows the potential value of community connections to bring and integrate external resources into rural communities, a condition for successful rural revitalisation. Taking into account the importance of the reverse flows of capitals from urban to rural areas, we wish to emphasise the necessity of interconnections between bonding and bridging social capital in the discourse of rural restructuring in which opening and cohesion of rural communities should be placed in the centre. Giving the increasing interests and flows of capital from urban-to-rural areas, we are concerned about the real possibility of "rural gentrification", referring to a process driven by those from the urban upper- or middle-class who pursue a perceived higher quality of life available in the countryside (Nelson et al., 2010). If it is true, the process of rural restructuring may lead to an increasing stratification and marginalisation in rural China, which rural poor in marginal areas may not gain benefit but in fact, suffer from.

Third, this paper offers insight to potential resources among university students for their home community development in countryside. Accounting for the nature of rural communities in terms of the complexity, diversity, and transition across China, our survey shows the heterogeneousness among university students in light of value systems, lifestyle preferences and career perspectives together with a number of other factors influencing or determining their attitudes, perceptions, and behaviours. However, no significant correlation is found between access to collective land, the change of hukou status, and the choice between rural and urban lifestyles. This seems to suggest: there is a complicated relationship between the three variables, 
and also the limitation of hukou being treated as the only indicator of rural identity. Compared with above factors, the important one is shared value or attachment to home communities. Furthermore, the correlation of the preference for rural lifestyle with high ranking universities and psychological pressure of living in urban areas seems to suggest a new or emerging momentum among university students who may be departing from conventional thinking and "urban bias", and concerned about the possibility of return migration to catch new opportunities in home communities. Further research is needed in order to explore and analyse the relationships between community connection, return migration, and innovation in home communities.

\section{Conclusion}

In the context of urbanisation, migration, and rural decline in the 21 st century, this paper draws attention to the phenomenon of community connection among migrants in urban China and examines the implications for rural revitalisation. Through the perspective of bridging social capital, we have developed a framework and indicators to reveal the nature, features, factors, and implications for home community development. Reflecting research questions posed at the beginning of this paper, a number of conclusions can be drawn as below.

Firstly, community connection provides a foundation upon which bridging social capital can be linked with and used for the development of home community, and an important condition for successful rural revitalisation in China.

Secondly, the value and potential of the community connection requests to recognise the sense of community among migrants who are attaching to, and willing to bring external resources into, home communities.

Thirdly, sense of community varies greatly with the geographic location and social group which migrants belong to. The higher sense of community is particularly amongst those 
from remote villages and rural poor whose livelihoods are heavily dependent upon traditional agriculture. Furthermore, differences in sense of community may lead to different approaches or attitudes to ongoing land transfer in China's countryside.

The research findings above have policy implications for empowering rural communities. These include: learning their voices, needs, potential, and resources including external social connections for bottom-up development; variation of community connection in terms of mobilising and integrating external resources by geographic location and social group of rural communities they belong to; the necessity of rebalancing rural-urban relationship for better using potential resources in urban areas and also avoiding "urban bias" and simplification in designing and implementing rural revitalisation.

We acknowledge that our survey data has some limitations and as a result, cannot provide a comprehensive view on community connection among rural students. Nonetheless, this paper demonstrates the value and interpretation of balance and interconnection between bridging and bonding social capital to account for the intrinsic dynamics within rural communities, interface and integration with other capitals/resources, and a promising direction for future research in China and other developing countries. 


\section{References}

Ahlers, A. L. 2015. Weaving the Chinese dream on the ground: Local government approaches to "new-typed" rural urbanisation, Journal of Chinese Political Sciences, 20: 121-142.

Bao, H. and Wang, F., 2017. Transfer from urban to rural hukou among university students and reversing urbanisation in China. China's Youth Stud. 3, 81-87 (in Chinese)

Bourdieu, P., 1986. The forms of capital, in Richardson, J.C. (Ed), Handbook of Theory and Research for the Sociology of Education. Greenwood Press, New York, pp. 241-258.

Brown, B.B., Altman, I., and Werner, C.M. 2012. Place attachment, in International Encyclopaedia of Housing and Home. Elsevier, Toronto, pp.183-188.

Carney, D. (ed.),1998. Sustainable Rural Livelihoods: What contribution can we make? Department for International Development, London.

Chung, H., 2014. Rural transformation and the persistence of rurality in China. Eurasian Geogr. and Econ. 54(5-6), 594-610.

de Haas H, 2010. Migration and development: A theoretical perspective. Int. Migr. Rev. 44(1), 227-264.

Hao, P., Geertman, S., Hooimeijer, P., and Sliuzas R., 2012. The land-use diversity in urban villages in Shengzhen. Env. and Plan. A. 44, 2742-2764.

Hao, P. and Tang S, 2015. Floating or setting down: the effect of rural landholding on the settlement intention of rural migrants in urban China. Env. and Plan. A. 47, 1979-1999.

Hua, Z, 2016. Political initial of the Ministry of Agriculture in promoting return migration and entrepreneurship among rural migrant workers and rural university students. Nongmin Daily, 23 July 2016 (in Chinese).

Kan, K., 2016. The transformation of village collective in urbanising China: A historical institutional analysis. J. Rural Stud. 47: 588-600. 
Levien, M., 2015. Social capital as obstacle to development: Brokering land, norms, and trust in rural India. World Dev. 74, 77-92.

Li, B.S., 2011. Reversing change of hukou status from urban to rural areas in the era of urbanisation. Anhui Normal University Academic Journal of Social Science Edition, 39(2), 238-242 (in Chinese).

Li, Y.H., Jia, L.R., Wu, W.H., Yan, J.Y., and Liu, Y.S., 2018. Urbanization for rural sustainability: rethinking China’s urbanization strategy. J. Clean. Product.178, 580-586.

Li, Y.H., Westlund, H., Zheng, X.Y., and Liu, Y.S., 2016. Bottom-up initiatives and revival in the face of rural decline: Case studies from China and Sweden. J. Rural Stud. 47, 506-513.

Liu, L. H., 2016a. Migration and land transfer among college students from the countryside. Scientific Press, Beijing (in Chinese).

Liu, L.H., 2016b. Urbanisation and land transfer among rural university students in China: A focus on the reverse change from urban to rural hukou and determinant factors behind. Population Stud. 38 (2), 101-112 (in Chinese).

Long, H.L. and Liu, Y.S., 2016. Rural restructuring in China. J. Rural Stud. 47, 387-391.

Long, H.L., Tu, S.S., Ge, D.H., Li, T.T. and Liu, Y.S., 2016. The allocation and management of critical resources in rural China under restructuring: Problems and prospects. J. Rural Stud. 47, 392-412.

McMillan, D.W., and Chavis, D.M., 1986. Sense of community: A definition and theory. J. Community Psych. 14(1), 6-23.

McMillan, D.W., 1996. Sense of community. J. Community Psych. 24(1), 315-325. National Bureau of Statistics of China (NBS), 2000-2017. Chinese Statistics Yearbook. China Statistics Press, Beijing. 
Nelson, P.B., Oberg, A., Nelson, L., 2010. Rural gentrification and linked migration in the United States. J. Rural Stud. 26, 343-352.

Onyx, J., 2005. Introduction, in Dale, A. (Ed), A Dynamic Balance: Social Capital and Sustainable Community Development. UBC Press, Vancouver, pp. 1-10.

Perkins, D.D. and Long, D.A., 2002. Neighbour sense of community and social capital: A multi-level analysis, in Fisher, A., Sonn, C. and Bishop, B (Eds.) Psychological Sense of Community: Research, Applications, and Implications. Plenum, New York, pp. 291-318. Prayitno, G., Matsushima, K., Jeong, H., and Kobayashi, K., 2014. Social capital and migration in rural area development. Proceia Env. Sci. 20, 543-552.

Putnam, R., 1995. Bowling alone: America's declining social capital. J. Democracy. 6(1), 65-78.

Story, W.T. and Carpiano, R.M., 2017. Household social capital and socioeconomic inequalities in child undernutrition in rural India. Soc. Sci. \& Medic. 181, 112-121.

Wang, X.G, and Li, T.H., 2012. Semi-urbanisation and rationale choice of rural migrant workers in China. Tianfu Academic J. 1, 111-114 (in Chinese)

Woods, M., 2005. Rural Geography: Processes, Responses and Experiences in Rural Reconstructing. Sage, London, Thousand Oaks and New Delhi.

Woods, M., 2009. Rural geography, In Kitchin, R., Thrify, N. Eds., International Encyclopedia of Human Geography, vol. 9. Elseview, Oxford, pp. 429-507.

Wu, B., 2003. Sustainable Development in Rural China: Farmer Innovation and Selforganization in Marginal Areas. RoutledgeCurzon, London.

Wu, B., and Pretty, J., 2004. Social connectedness in marginal rural China: The case of farmer innovation circles in Zhidan, north Shaanxi. Agr. and Human Val. 21, 81-92.

Ye, J. Z., 2015. Land transfer and the pursuit of agricultural modernisation in China. J. Agr. Change, 15(3), 314-337. 